\title{
Identifying a classic in history, philosophy, and social studies of science
}

\author{
Luciano Boschiero $^{1} \cdot$ K. Brad Wray ${ }^{2}$
}

Published online: 19 June 2018

(C) Springer Nature B.V. 2018

Aside from standard-length reviews, Metascience commissions longer essay reviews, survey reviews of two or more books, and symposia, in which a book author responds to a panel of reviewers. Additionally, we occasionally commission reviews of 'classics'; books widely believed to have made — and continue to makea significant impact in one or more of our combined fields of history, philosophy, and social studies of science. Each review of a 'classic' is a reminder of the historical formation of those fields.

We believe that Jack Birner's review of Karl Popper's The Poverty of Historicism (1957) fulfils this purpose perfectly. We commissioned this review 60 years after the book was first published. The production process, including the appearance of all our reviews online first, has carried the publication of Birner's review into the 61st anniversary of the book's existence. Birner reminds us of Popper's personal story, his intellectual formation, as well as the forcefulness and legacy of his arguments. Popper's legacy is difficult to determine, as is the case for so many ground-breaking authors. For most, he would be best remembered as the author of Logik der Forschung (1934), but for social and political theorists, he is instead often admired for The Open Society and Its Enemies (1945). Birner reminds us that the intellectual interests behind those works were related. Popper's main project during World War II and in the aftermath of the war, was to measure the methodologies of the social sciences, especially economics, against the standards of empirical science set out in Logik. While sympathetic towards economics, Popper was not tolerant of the Marxist historiographical approach equating social and political history with the natural sciences-supposing that all history develops according to logical and

Luciano Boschiero

1.boschiero@campion.edu.au

K. Brad Wray

kbwray@css.au.dk

1 Campion College, Sydney, Australia

2 Department of Mathematics, Centre for Science Studies, Aarhus University, Aarhus, Denmark 
rationally determinable ends. Finally, Birner examines the modern applicability of Popper's work in this area.

This Issue of Metascience also contains two standard reviews of books examining Thomas Kuhn's intellectual life (Alex Levine) and the continued scholarly interest in Kuhn's Structure of Scientific Revolutions (William Rehg). This topic creates an interesting dichotomy within this Issue, especially amid the variety of reviews that reflect the diversity of the discipline which has expanded significantly since the high-points of Kuhn's and Popper's careers in the middle of the twentieth century.

As always, we would like to acknowledge our debt to all our reviewers, in this and in previous Issues. Your contributions are especially appreciated in an era when an academic's expanding duties and obligations regularly impinge upon time that might otherwise be reserved for careful reading and reflection of others' works.

Thanks again also to all the publishing houses willing to send review copies, and especially to Springer and its staff for their continued generous support. 